\title{
Reducing Hydroelastic Response of Very Large Floating Structure: A Literature Review
}

\author{
H. Tavana \\ Department of Civil Engineering \\ Shahid Bahonar University, Kerman, Iran
}

\author{
M. J. Khanjani \\ Department of Civil Engineering \\ Shahid Bahonar University, Kerman, Iran
}

\begin{abstract}
Floating structure is applied as floating wave breaker, floating airport and etc. Applications of these structures rise because of being environmental friendly and fast construction. To design floating structure first step is hydrodynamic analysis under wave effect. As the depth of structure is too smaller than the other dimensions, this structure behaves elastically. Hydroelastic analysis is used to obtain its deformation under wave action. Reduction of the hydroelastic responses may increase serviceability and safety. There are many ways to reduce the hydroelastic response of VLFS. This paper was considered the analysis and hydroelastic reduction of VLFS.
\end{abstract}

\section{Keywords}

Hydroelastic, floating structure, hydrodynamic force

\section{INTRODUCTION}

Engineers and designers are dealing with lack of land due to rise of population and urban development. Island country and country which have long coastline use land reclamation technology for solving the scarcity of land [1]. Very large floating structure (VLFS) technology is alternative solution for reclamation technology. By using this technology land can create from the sea without need of huge volume of material. VLFS technology can be used for different purpose such as floating airport, floating bridge and floating storage facility [2]. VLFSs are artificially man-made land parcels on the sea. They appear like giant plates resting on the sea surface [3]. There are basically two types of VLFS, namely the semisubmersible-type and pontoon-type (Fig.1) [4]. Semisubmersible-type has ballast column tubes to raise the platform above the water level and suitable for use in open seas where the wave heights are relatively large. In contrast, the pontoon-type VLFS platform rest on the water surface and are used in calm waters such as in a cove and a lagoon [3].

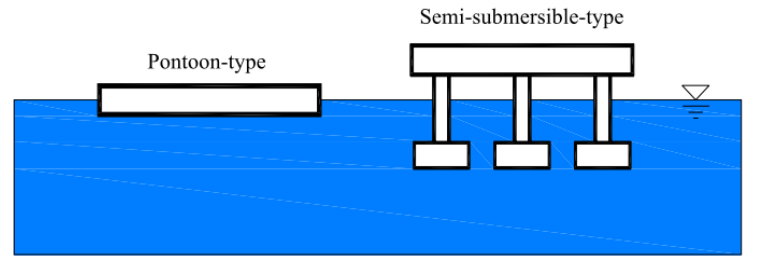

Fig.1 Types of VLFS [6]

\section{VLFS APPLICATION, ASSUMPTION}

First time Edward Armstrong in 1920 proposed an airport for aircrafts flying across the oceans. In the second world war the US Navy Civil Engineering Corps used this idea to construct floating pontoon flight deck $552 \mathrm{~m} * 83 \mathrm{~m}^{*} 1.5 \mathrm{~m}$ with draft of
$0.5 \mathrm{~m}$. Japanese engineers construct a floating runway in Tokyo bay (Fig.2) for testing a floating airport. Construction was initiated in 1998 and finished at the end of 1999 [5]. VLFS also is applied as floating bridges. They are economical when the water depth is large or the river/seabed is very soft [3]. Pontoon floating bridge is the earliest application of pontoon-type VLFS. The first floating bridge is king Xeroxes' floating boat bridge (Fig.3) across Hellespont (about 480 B.C.) [6].

One more application of very large floating structures is the floating storage facility. VLFSs have already been used for storing fuel (Fig.4). An offshore oil storage facility is constructed like flat box-shaped tankers connected to each other and to other components of the VLFS system [6].

The most innovative application of VLFS is the floating city. By using this technology future large human habitation can construct on the ocean surface. The Lilypad Floating Ecopolis proposed by the Belgium architect Vincent Callebaut, is an example of visionary proposition to house the city population on huge floating lily-shaped island (Fig.5) [3].

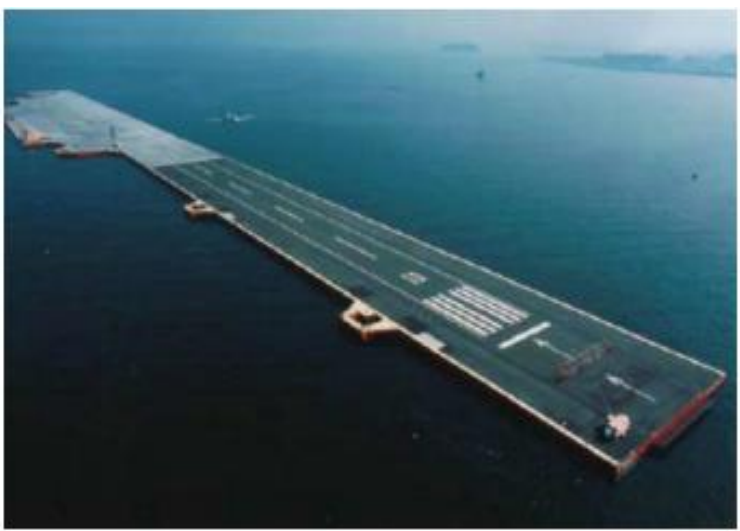

Fig.2 Mega Float Tokyo Bay, Japan [6] 


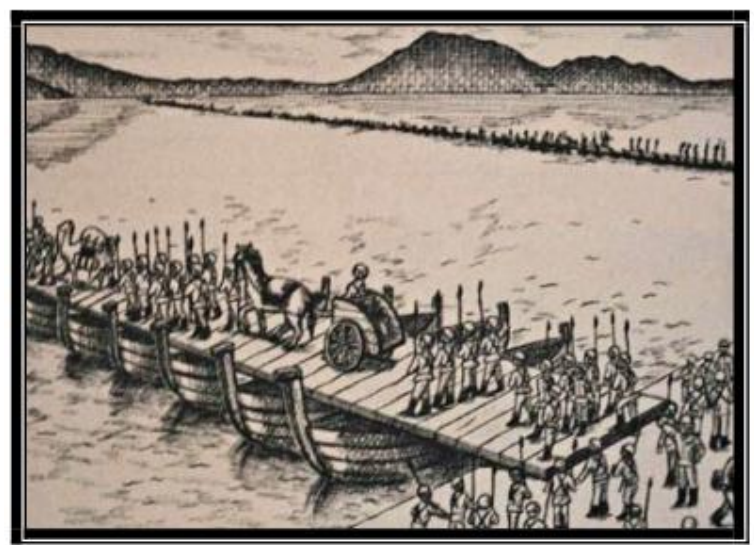

Fig.3 King Xerxes' Floating Boat Bridge across the Hellespont [2]

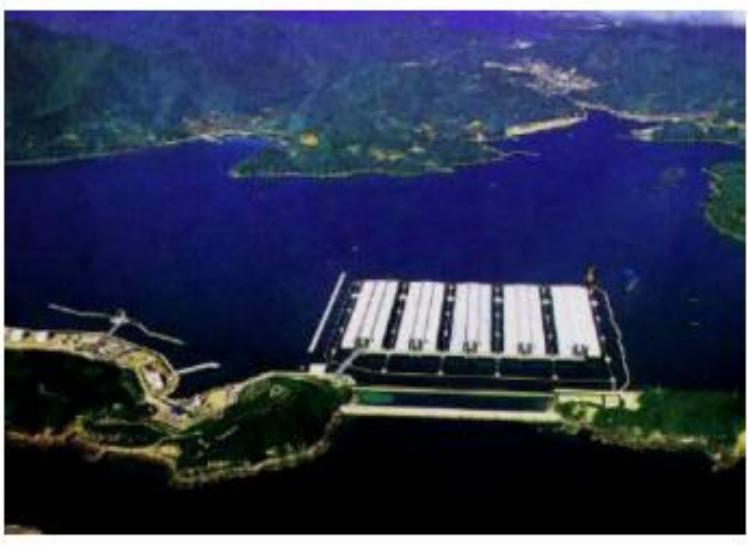

Fig.4 Floating Oil Storage Base at Kamigoto, Japan [6]

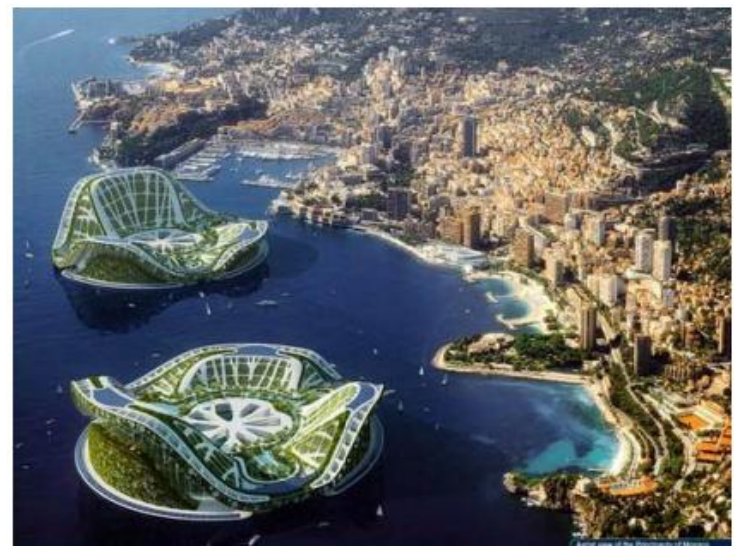

Fig.5LilypadFloating Ecopolis [3]

\section{HYDROELASTIC RESPONSE}

The hydroelastic response of a floating structure is affected by several factors such as wave period, water depth and structural rigidity. The effects of wave period and water depth on hydroelastic response of floating structure are studied by Hermans [7] and Andrianov and Hermans [8]. It was reported that, as wavelength becomes longer, the deflection becomes larger. Also the elastic deformation increases as the water depth increases, i.e. structure displacement in deep water is longer than in shallow water at the same incident wave length [8]. Liu and Sakai found that the hydroelastic response decreases as the flexural rigidity of structure increases [9].

\subsection{Hydroelastic Analysis}

As the depth of structure is too smaller than the other dimensions (length and width) thin plate theory can be used to perform the analysis. For more accuracy the Mindlin (thick) plate theory can be applied (see Watanabe et al. [10] and Zhao et al. [11]). There are two approaches to analyze VLFSs, frequency domain approach and time domain approach. Most hydroelastic analysis is carried out in frequency domain, because of its simplicity and being cost effective. In order to perform hydroelastic analysis in frequency domain, there are two parts needed to model: fluid part and the floating structure part. There are two methods to solve this problem: the modal expansion and direct method [12]. The modal expansion method consists of separating the hydrodynamic analysis and dynamic response analysis of the plate. For the direct method, problem is solved directly without expanding the plate motion into eigenmodes. In the time-domain analysis, the commonlyused approaches are the direct time integration method and Fourier transform method. In the direct time integration method, the equations of motion are discretized for both the structure and the fluid domain. In the Fourier transform method, the frequency domain solutions are first obtained for the fluid domain and then the results are inserted into the differential equations for elastic motion [6]. Frequency domain can be seen in studies of Meylan and Squire [13], Ohmatsu [14], Andrianov and Hermans [8] and Chen et al. [15]. On the other hand for transient response and for nonlinear equations of motion due to the effects of mooring system or nonlinear wave, it is necessary to perform the analysis in the time domain [1]. The proponents of time domain approach are Endo [16], Liu and Sakai [9], Kyoung et al. [17], Qiu and Liu [18].

\subsection{Hydroelastic reduction}

For most application it is desirable to reduce hydroelastic response of VLFS. A reduce in hydroelastic response will translate to increase in safety and improvement in the serviceability levels of VLFS [19]. There are some ways in reducing deflection and stresses. The most conventional approach is by increasing the structural stiffness of the floating structure [9]. The traditional way is using breakwaters which reduce the height of incident water waves. The breakwaters may be a bottom-founded [20] or a floating oscillating-water-column (OWC) [21, 22]. Hong et al. [21] found that the length of the horizontal plate in the floating OWC has a significant influence on the reduction of the hydroelastic response of the floating structure. Based on these findings, they suggested that a reverse T-shape floating breakwater may be an interesting alternative for protecting a VLFS. They also suggested that the reduction effect may be significantly improved by connecting the floating breakwater system to the floating structure with a pin-connection which was further investigated by Hong and Hong [22].

Wang et al. [4], proposed an innovative solution to reduce the differential deflection so-called gill cells which are compartments in the floating structure with holes or silts at their bottom floors that allows water to flow in and out freely. They showed that, these gill cells reduce the deflection and bending stresses significantly.

Another innovative approach for reducing the hydroelastic response of floating structure is by using semi-rigid connections in floating structure system instead of rigid connection. The investigation of hydroelastic of articulated floating structure can be found in Lee and Newman [23], Xia 
et al. [24], Fu et al. [25], Kim et al. [26] and Karmakar et al. [27]. These studies were concerned more on the hydroelastic behavior not hydroelastic reduction. Hydroelastic reduction of floating structure with semi-rigid connectors was studied by Furkawa et al. [28], Khabakhpasheva and Korobkin [29], Kim et al. [30] and Gao et al. [31]. Khabakhpasheva and Korobkin modeled plate by an Euler beam and investigated the hydroelastic response reduction of a main floating beam by using an auxiliary floating beam. Two approaches aimed to reduce the beam vibrations were described in their study. In the first approach, an auxiliary floating plate is added to the main structure. Within the second approach the floating beam is connected to the sea bottom with a spring, the rigidity of which can be selected in such a way that deflections in the main part of the floating beam are very small. The effects of the auxiliary beam placement (the front end or the rear end of the main floating beam), length, flexural rigidity, and the connection rotational stiffness characteristic were studied. The study revealed that an auxiliary floating beam located at the front end of the main beam leads to a reduction in the response whereas the auxiliary floating beam at the rear end increases the response. They also found that stronger reduction is observed when a hinge connection is used to join the auxiliary floating beam to the main floating beam. Furthermore, a long and rigid auxiliary beam gives a better reduction of the main floating beam response than a shorter and flexible one [29].

Kim et al. [30] studied hydroelastic response reduction of a floating plate using a line hinge-connected auxiliary plate at the front end. They found that the most effective reduction was observed when there are two auxiliary plates and when the auxiliary floating plate has a semi-circular shape. Riyansyah et al. [19] investigated the connection design for a two-floating beam system to minimize hydroelastic response. Also they studied the effect of relative beam stiffness on hydroelastic response of two-floating beam system. Gao et al. [31] studied the hydroelastic response of pontoon-type, very large floating structures with a flexible line connection. They also studied the effects of the location and the rotational stiffness of such a flexible line connection on the hydroelastic response. Results showed that hinge and semi-rigid line connection are effective in reducing hydroelastic response of the VLFS as well as the stress resultant.

Another interesting solution is to attach a deep draft antimotion device on edge or bottom surface of the floating structure. The purpose of these devices is to reflect the incident wave so, only small portion of wave energy propagates beneath the floating structure. The proponents of this approach are Ohta et al. [32, 33], Utsunomiya et al. [34], Takagi et al. [35], Watanabe et al. [36] and Pham et al. [37]. Ohta et al. [33] proposed a reverse T-shape device, an Lshape, a reverse-L-shape, and a beach-type plated structure as anti-motion devices. The results showed that the hydroelastic response of the floating structure is effectively reduced not only at the edges, but also in the inner parts as well. They concluded that L-shape plate anti-motion device is more effective against long waves whereas the beach-type and reverse-L-shape anti-motion devices are more effective against short waves. Takagi et al. [35] proposed a boxshaped anti-motion device attached to fore end of VLFS. They investigated the effects of this device theoretically and experimentally. Both experimental results and the theoretical results showed that the anti-motion performance of this device is very good. The theory also demonstrated that this device reduces not only the deformation but also the shearing force and the moment of the platform. Pham et al. [37] proposed an inclined anti-motion device and performed experiment tests to assess its performance against the other types of anti-motion devices proposed by [33]. It was found that the inclined antimotion device is the most effective when compared to the other devices (Fig.5). Tavana and Khanjani [38] studied the different connection angel of inclined plate in different freedom degree. The results showed, the inclined plate with $45^{\circ}$ is effective in Heave freedom degree (Fig.6) and in Surge, Roll and Yaw freedom degrees, inclined plate with $60^{\circ}$ connection angel has more reduction in shear force and moment.

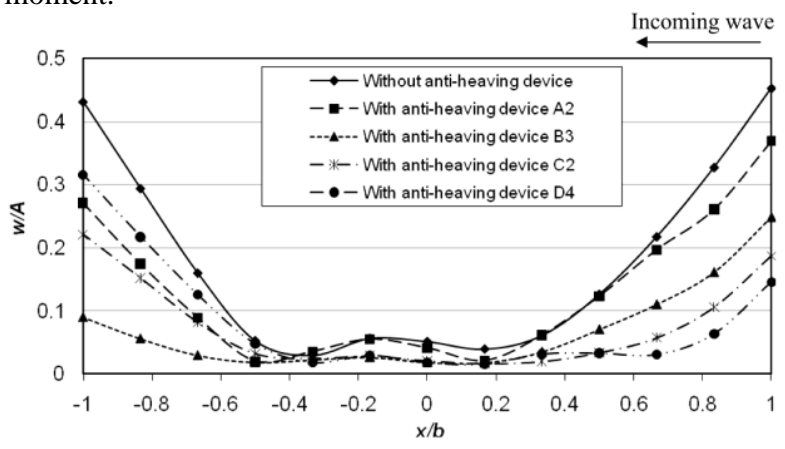

Fig. 5 Nondimensionalized deflection amplitude of VLFS without and with anti-heaving device

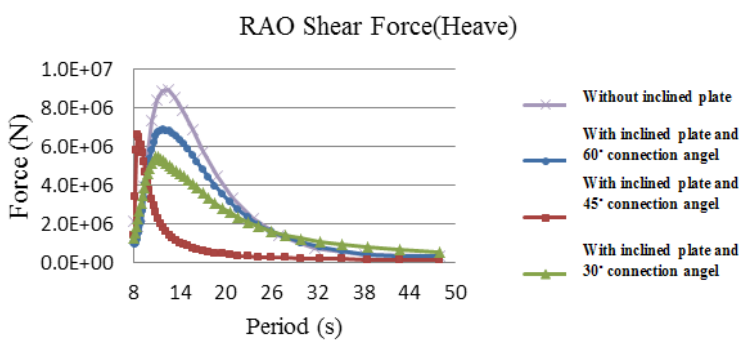

Fig. 6 Shear force of VLFS with and without inclined plate

\section{CONCLUSION REMARK}

Hydrodynamic wave force and structure deformation are important factors in designing of VLFS. VLFS response can't be considered as rigid body dynamics solely and hydroelastic analyze should be performed. In most applications, reducing hydroelastic response may increase safety and serviceability. In this paper different hydroelastic reduction methods were studied. By using these methods, hydroelastic response of VLFS can be reduced and breakwater may be eliminated.

\section{REFERENCES}

[1] Watanabe, E., Utsunomiya, T., and Wang, C. M. (2004). Hydroelastic analysis of pontoon-type VLFS: a literature survey. Engineering structures, 26(2), 245-256.

[2] Watanabe, E., Wang, C. M., Utsunomiya, T., and Moan, T. (2004). Very large floating structures: applications, analysis and design. CORE Report, 2.

[3] Wang, C. M., and Tay, Z. Y. (2011). Very Large Floating Structures: Applications, Research and Development. Procedia Engineering, 14, 62-72.

[4] Wang, C. M., Pham, D. C., and Ang, K. K. (2007). Effectiveness and optimal design of gill cells in minimizing differential deflection in circular VLFS. Engineering structures, 29(8), 1845-1853. 
[5] Shipbuilding Research Centre of Japan (2003), MegaFloat Home Page [Online], available at: http://www.srcj.or.jp/html/megafloat_en/index.html.

[6] Pham, D. C. (2009). Innovative Solutions For Minimizing Differential Deflection And Heaving Motion In Very Large Floating Structures, Ph.D. Thesis, National University of Singapore, Singapore.

[7] Hermans, A. J. (2001). A geometrical-optics approach for the deflection of a floating flexible platform. Applied ocean research, 23(5), 269-276.

[8] Andrianov, A. I., and Hermans, A. J. (2003). The influence of water depth on the hydroelastic response of a very large floating platform. Marine Structures, 16(5), 355-371.

[9] Liu, X., and Sakai, S. (2002). Time domain analysis on the dynamic response of a flexible floating structure to waves. Journal of engineering mechanics, 128(1), 48-56.

[10] Watanabe, E., Utsunomiya, T., Wang, C. M., and Hang, L. T. T. (2006). Benchmark hydroelastic responses of a circular VLFS under wave action. Engineering structures, 28(3), 423-430.

[11] Zhao, C. B., Zhang, J. Z., and Huang, W. (2007). Vibration Reduction of Floating Elastic Plates in Wave Waters. Marine Structures, 20, 71-99.

[12] Wang, C. M., Watanabe, E., and Utsunomiya, T. (Eds.). (2007). Very large floating structures. Taylor and Francis.

[13] Meylan, M., and Squire, V. A. (1994).The response of ice floes to ocean waves. Journal of Geophysical Research: Oceans (1978-2012), 99(C1), 891-900.

[14] Ohmatsu, S. (2000). Numerical calculation method for the hydroelastic response of a pontoon-type very large floating structure close to a breakwater. Journal of marine science and technology, 5(4), 147-160.

[15] Chen, X., Moan, T., Fu, S., and Chui, W. (2005). Hydroelastic analysis of flexible floating structures in regular waves. In Proceedings of International Conference on Mechanical engineering and mechanics (pp. 973-977).

[16] Endo, H. (2000). The behavior of a VLFS and an airplane during takeoff/landing run in wave condition. Marine structures, 13(4), 477-491.

[17] Kyoung, J. H., Hong, S. Y., and Kim, B. W. (2006). FEM for time domain analysis of hydroelastic response of VLFS with fully nonlinear free-surface conditions. International Journal of Offshore and Polar Engineering, 16(3).

[18] Liuchao, Q., and Hua, L. (2007). Three-dimensional time-domain analysis of very large floating structures subjected to unsteady external loading. Journal of offshore mechanics and Arctic engineering, 129(1), 2128.

[19] Riyansyah, M., Wang, C. M., and Choo, Y. S. (2010). Connection design for two-floating beam system for minimum hydroelastic response. Marine Structures, 23(1), 67-87.

[20] Nagata, S., Yoshida, H., Fujita, T., and Isshiki, H. (1998). Reduction of the motion of an elastic floating plate in waves by breakwaters. In Proceedings of the 2nd International Conference on Hydroelasticity in Marine Technology (pp. 229-238).

[21] Hong, D. C., Hong, S. Y., and Hong, S. W. (2006). Reduction of hydroelastic responses of a very-long floating structure by a floating oscillating-water-column breakwater system. Ocean engineering, 33(5), 610-634.

[22] Hong, D. C., and Hong, S. Y. (2007). Hydroelastic responses and drift forces of a very-long floating structure equipped with a pin-connected oscillatingwater-column breakwater system. Ocean engineering, 34(5), 696-708

[23] Lee, C. H., and Newman, J. N. (2000). An assessment of hydroelasticity for very large hinged vessels. Journal of fluids and structures, 14(7), 957-970.

[24] Xia, D., Kim, J. W., and Ertekin, R. C. (2000). On the hydroelastic behavior of two-dimensional articulated plates. Marine structures, 13(4), 261-278.

[25] Fu, S., Moan, T., Chen, X., and Cui, W. (2007). Hydroelastic analysis of flexible floating interconnected structures. Ocean engineering, 34(11), 1516-1531.

[26] Kim, B. W., Young Hong, S., Kyoung, J. H., and Kyu Cho, S. (2007). Evaluation of bending moments and shear forces at unit connections of very large floating structures using hydroelastic and rigid body analyses. Ocean engineering, 34(11), 1668-1679.

[27] Karmakar, D., Bhattacharjee, J., and Sahoo, T. (2009). Wave interaction with multiple articulated floating elastic plates. Journal of Fluids and Structures, 25(6), 1065-1078.

[28] Furukawa, T., Yamada, Y., Furuta, H., and Tachibana, E. (1999). Experimental study on vibration control of unitlinked floating structures. In First International Conference on Advances in Structural Engineering and Mechanics (pp. 833-838).

[29] Khabakhpasheva, T. I., and Korobkin, A. A. (2002). Hydroelastic behaviour of compound floating plate in waves. Journal of engineering mathematics, 44(1), 21-40.

[30] Kim, B. W., Kyoung, J. H., Hong, S. Y., and Cho, S. K. (2005). Investigation of the Effect of Stiffness Distribution and Structure Shape on Hydroelastic Responses of Very Large Floating Structures. In Proceedings of 15th International Offshore and Polar Engineering Conference (pp. 210-217).

[31] Gao, R. P., Tay, Z. Y., Wang, C. M., and Koh, C. G. (2011). Hydroelastic response of very large floating structure with a flexible line connection. Ocean Engineering, 38(17), 1957-1966.

[32] Ohta, H., Torii, T., Hayashi, N., Watanabe, E., Utsunomiya, T., Sekita, K., and Sunahara, S. (1999). Effect of attachment of a horizontal/vertical plate on the wave response of a VLFS. Proceedings 3rd International Workshop Very Large Floating Structure, University of Hawaii at Manao, Honolulu, Hawaii, USA, 265-274.

[33] Ohta, M., Ozaki, M., Matsura, M., Tanigaki, S., Shuku, M., and Inoue, S. (2002, May). A study on progress in anti-wave performance of Mega-float. In Proceedings of the $12^{\text {th }}$ International Offshore and Polar Engineering Conference (pp. 275-282).

[34] Utsunomiya, T., Watanabe, E., Kuramoto, M., Sunahara, S., Sekita, K., Hayashi, N., and Ohta, H. (2000). Wave response analysis of an elastic floating body with submerged horizontal plate. In Soc Naval Arch Japan, Proc 15 th Ocean Engineering Symposium (pp. 179184).

[35] Takagi, K., Shimada, K., and Ikebuchi, T. (2000). An anti-motion device for a very large floating structure. Marine structures, 13(4), 421-436.

[36] Watanabe, E., Utsunomiya, T., Kuramoto, M., Ohta, H., Torii, T., and Hayashi, N. (2003). Wave response analysis of VLFS with an attached submerged plate. International Journal of Offshore and Polar Engineering, 13(3).

[37] Pham, D. C., Wang, C. M., and Bangun, E. P. (2009). Experimental study on anti-heaving devices for very 
large floating structure. The IES Journal Part A: Civil and Structural Engineering, 2(4), 255-271.
[38] Tavana H. and Khanjani, M. J. (2013). Effect of inclined plate attached to VLFS on RAO. Proceedings of the $7^{\text {th }}$ National Congress on Civil Engineering, Zahedn, Iran. 